\title{
Caso: análise da estivasem de celulose no Porto do Itaqui, em São Luís (MA)
}

Case: cellulose loading analysis in
the Port of Itaqui - São Luís (MA)

\section{Caso: análisis del ejercicio de celulosa en el Puerto del Itaqui, en San Luis (MA)}

\author{
Vitor Renato Pereira Santos \\ Graduado em Engenharia Mecânica \\ Alvino Oliveira Melo \\ In memoriam \\ Instituto Federal do Maranhão
}

Resumo Este artigo analisa o processo de estivagem de celulose no Porto do Itaqui, localizado em São Luís (MA) para determinação de ações para se reduzir esses custos pelo menor tempo de carregamento, aumentando a rotatividade de navios no porto e a rentabilidade da operação, contribuindo para que a empresa seja mais competitiva no mercado marítimo. Para tanto, foram estudadas técnicas de estivagem, observando as diversas operações de carregamento de celulose em diferentes regimes de trabalho. Da mesma forma, acompanharam-se as várias interrupções ocorridas durante as operações relativas às intervenções para manutenção das máquinas e equipamentos (guindastes, lifting frames ou spreaders). A eficiência da cadeia de estivagem foi medida com o emprego da ferramenta Overhaul Equipment Effectiveness - OEE, que permite a estimativa da eficácia dos equipamentos e da operação. Concluímos pela necessidade de desenvolvimento e implantação de técnicas e tecnologias inovadoras na melhoria da qualidade do andamento desse tipo de operação portuária e da gestão da empresa, com a utilização de indicadores que conectem os envolvidos no processo produtivo.

Palavra-chave: Estivagem. Celulose. Oterhaul Equipment Effectiveness - OEE. Porto DO ITAQui.

Aвstract This paper approaches the cellulose loading process in the Port of Itaqui, located at São Luís (MA), in order to specify actions for costs reduction by lesser loading time, by increasing ships rotativity in the port and the operation cost-effectiveness, contributing to a higher port competitivity in the maritime market. So, it was studied loading techniques regarding the various cellulose loading operations in different ways of working. As well, it was controlled the many operations stoppages due equipment maintenance (cranes, lifting frames or spreaders). 
The loading chain efficiency was measured using the Overhaul Equipment Effectiveness OEE tool, which allows to calculate the equipment and operation effectiveness. We concluded that developing and implementation of innovative techniques and technologies are required for improving the quality in this kind of port operation and management, with indicators capable to connect all parts involved in productive processes.

Keywords: Loading. Cellulose. Overhaul Equipment Effectiveness - OEE. Port of Itaqui.

Resumen Este artículo analiza el proceso de estiramiento de celulosa en el Puerto de Itaqui, ubicado en São Luís (MA) para determinar las acciones para reducir estos costos por el menor tiempo de carga, aumentando la rotación de buques en el puerto y la rentabilidad de la operación, contribuyendo para que la empresa sea más competitiva en el mercado marítimo. Para ello, se estudiaron técnicas de estiramiento, observando las diversas operaciones de carga de celulosa en diferentes regímenes de trabajo. De la misma forma, se acompañaron las varias interrupciones ocurridas durante las operaciones relativas a las intervenciones para el mantenimiento de las máquinas y equipos (grúas, lifting frames o spreaders). La eficiencia de la cadena de estiba se midió con el empleo de la herramienta Overhaul Equipment Effectiveness - OEE, que permite la estimación de la eficacia de los equipos y de la operación. Concluimos por la necesidad de desarrollo e implantación de técnicas y tecnologías innovadoras en la mejora de la calidad del progreso de este tipo de operación portuaria y de la gestión de la empresa, con la utilización de indicadores que conecten a los involucrados en el proceso productivo.

Palabra clave: Estiramiento. la celulosa. Overhaul Equipment Effectiveness - OEE. Puerto de Itaqui.

\section{INTRODUÇÃO}

O transporte aquaviário tem a finalidade de deslocar mercadorias entre portos distintos, marítimos ou fluviais, em um espaço de tempo acordado, assegurando-se que a carga seja entregue em perfeitas condições físicas. Mitigando qualquer que seja o prejuízo e visando o menor custo possível, o transporte aquaviário é a opção economicamente viável quando se trata de grandes volumes de carga.

Os navios mais inovadores têm motores mais econômicos, que possibilitam navegações mais rápidas com cascos hidrodinâmicos e ajustes de trim ou adernamento. Há também condições de maior segurança pela redução de possibilidades de tombamentos, acidentes fatais, colisões entre navios. Além do avanço tecnológico das embarcações, também ocorreu a melhoria da infraestrutura dos portos brasileiros.

Este estudo tem como foco o Porto do Itaqui, situado a 11 quilômetros do centro da Cidade de São Luís (Brasil), com 1.614 m de cais, profundidades de 9 m a $21 \mathrm{~m}$ nas variações das marés. Além de ser considerado um dos portos mais profundos do mundo, possui vantagem também em relação a outros portos do sudeste do Brasil pela sua localização geográfica. Por situar-se na costa norte do Brasil, permite diminuição em até sete dias de viagem para os maiores portos do mundo, por exemplo o de Roterdã. Em 2012, o porto inaugurou o Berço 100, que também é utilizado para a movimentação de celulose, nosso objeto de estudo. Em 2014, o TEGRAM (Terminal de Grãos do Maranhão) com capacidade para 10 milhões de t/ ano começou seu funcionamento. 


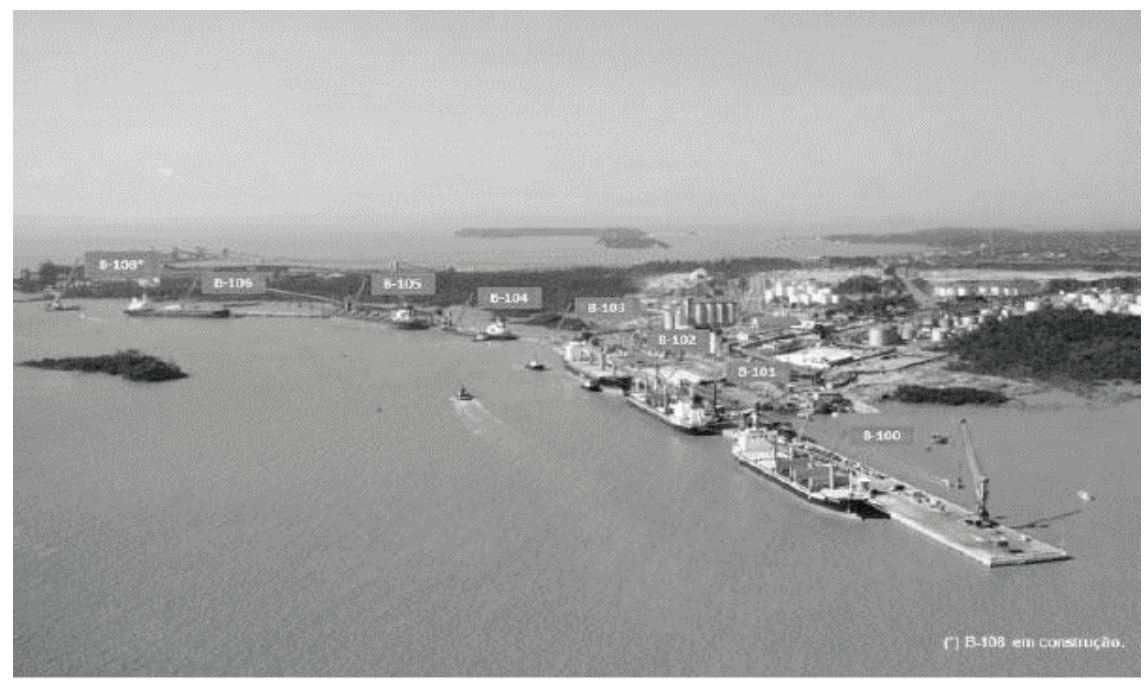

Figura 1 - Vista aérea do porto do Itaqui.

Fonte: EMAP - Empresa Maranhense de Administração Portuária.

Acompanhando a evolução das embarcações e das estruturas portuárias, em meados de 1950-1960 iniciam-se os estudos das técnicas e conceitos empregados na logística pelo crescimento da demanda de produtos industrializados e também da concorrência empresarial e importância da qualidade do produto. Com o passar dos anos, os compradores começaram a levar mais em consideração a qualidade do produto ofertado, assim como, o fator custo $\mathrm{x}$ benefício além da acessibilidade ao produto. Desse modo, o cliente e a concorrência forçam as empresas a buscarem meios para baratear o seu produto e a ter um maior alcance territorial, destarte elas procuraram desenvolver seus canais de distribuição.

O canal de distribuição é um fator integrante da cadeia logística que é composta pelos fabricantes, atacadistas, distribuidores, varejistas e consumidor final. Tem como função também induzir a demanda, satisfazer a demanda, disponibilizar serviços pós compra e trocar informações. Segundo Rojas (2014), os canais de distribuição disponibilizam produtos com rapidez, reforçam o potencial de vendas, fortalecem a cooperação entre os componentes da cadeia logística, facilitam o fluxo de informação e de material, e reduzem os custos logísticos (ROJAS, 2014, p. 3).

Os canais de distribuição que servem aos portos responsáveis pelo deslocamento de carga devem funcionar harmoniosamente, tendo sintonia entre a linha de produção da fábrica até o momento de estivagem. A fábrica deve conseguir alimentar o seu armazém portuário, para que haja sempre carga para estivar o navio em tempo hábil.

Este é o nosso problema: o embarque de celulose pela empresa G5 Logística, responsável por transportar a celulose da empresa Suzano, situada em Imperatriz-BR, até o armazém da mesma empresa, localizado no Porto do Itaqui, deve manter volumes suficientes para embarque da carga em navios fretados por diferentes clientes. $\mathrm{O}$ foco do trabalho é na estivagem da celulose.

Assim, este trabalho tem como objetivo analisar e propor soluções para evitar interrupções na operação de embarque, como pausas para a manutenção nos spreaders, nos guindastes, ou para 
reencaixar os grampos na carga, além de facilitar ao operador do guindaste o posicionamento das cargas nos porões do navio por meio de sistemas mecânicos para içamento uniforme.

\section{Material e mÉtodos}

A empresa G5 Logística autorizou a pesquisa, liberando o acesso ao porto e aos navios junto à EMAP. A operação de estivagem foi analisada, utilizando o método de pesquisa de participação observante, visando identificar os aspectos que poderiam ser melhorados, destacando-se aqueles possíveis de serem ajustados não apenas sob o ponto de vista da execução, mas de custos envolvidos. Consideraram-se, também, quais informações da empresa eram acessíveis, respeitando-se a política de privacidade de algumas informações da empresa.

A revisão bibliográfica sobre os temas pertinentes baseou-se em autores como Pablo Rojas, Huerbton Couto, Glaydston Ribeiro, Luiz Lorena, Handabaka entre outros. Rojas (2014) introduz noções a respeito de logística e seus modais, acerca do sistema portuário brasileiro e comércio internacional. Discorre sobre movimentação de carga, operações de embarque e desembarque, além de abordar questões administrativas, leis e impostos associados a cada operação. Couto (2007) destaca que o manuseio das cargas é otimizado com unitização de cargas, definido por ele como "o processo de agregar volumes fracionados em uma única unidade de carga, mantida inviolável ao longo de todo percurso origem/destino” (p. 14). Este trabalho contribuiu no aspecto da compreensão por que a celulose é transportada dessa forma, quais os benefícios da unitização e de se pensar na possibilidade de pequenos ajustes nesse método.

\section{LOCAL DE PESQUISA}

O local de pesquisa foi o Porto do Itaqui, no qual o navio da Figura 2 encontrava-se atracado no Berço 100. É nesse local que ocorre a maioria das operações de estivagem de celulose, que também acontecem no Berço 103. No porto, a celulose é transportada em caminhões do armazém até a beira do cais (Figuras 2 e 3). No caso, o carregamento está sendo feito simultaneamente nos porões 5 e 8 da embarcação. Essa distribuição de carga já foi previamente calculada pelo Supercargo do navio e acordada com a Suzano e com a G5, pois como, no geral, um navio atende a mais de um comprador, há de se respeitar a ordem de embarque e de desembarque no porto de destino.

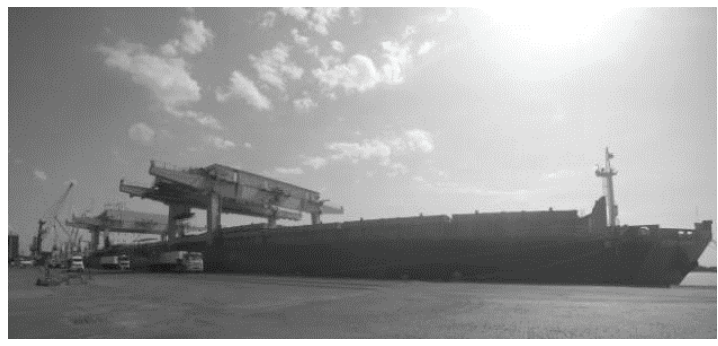

Figura 2 - Navio da empresa Star Hansa.

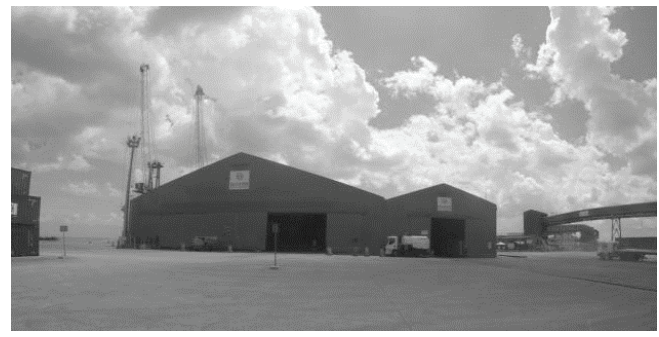

Figura 3 - Armazém da Suzano. 
A carga estivada é a celulose do tipo Suzano Pulp (Figura 4) de modo unitizado (Figura 5) por um sistema de amarração com arames. Cada conjunto de unidades de celulose é chamado de "lingada". Segundo a disposição, a lingada pode ser espelhada ou não espelhada, possuindo as dimensões em torno de 5,54m x 1,34m x 1,70m, pesando aproximadamente $12 \mathrm{~T}$. Observa-se que essas medidas podem variar de acordo com o tamanho do porão do navio. Divididas em outra categoria, a celulose exportada pode ser encapada ou não, dependendo do pedido do cliente.

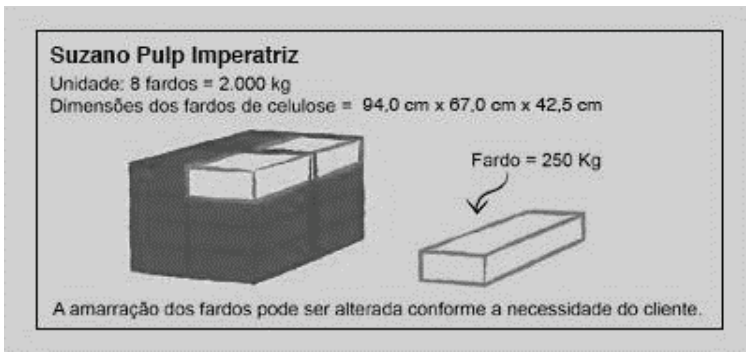

Figura 4 - Dimensões do fardo.

Fonte: Sítio da Suzano.

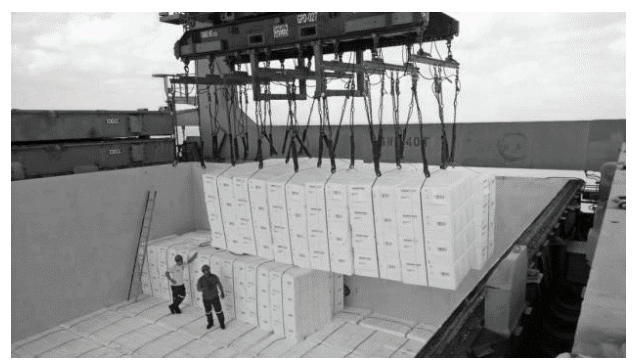

Figura 5 - Lingada de celulose.

\section{DescriçÃo da operaç̧̃̃o de EStivagem}

Entende-se por estivagem a arrumação da carga nos porões do navio. Antes de a carga ser estivada, ocorreu o carregamento desde a fábrica até a sua estivagem no porão do navio. O envio da carga para o porto, qual seja, o deslocamento de carga deve atender à capacidade de produção da fábrica e de seus armazéns e a chegada do navio para estivagem. A fábrica deve conseguir alimentar o seu armazém para que haja sempre carga o suficiente para estivar o navio em tempo hábil.

Este trabalho concentrou-se na operação da empresa G5 Logística, responsável por estivar a celulose da Suzano situada em Imperatriz/MA. A celulose é transportada até o seu armazém localizado no Porto do Itaqui, pela empresa VLI, e a empresa G5 realiza o embarque da carga em navios fretados por vários clientes.

O processo de estivagem não é feito aleatoriamente, a operação obedece a um fluxo que se inicia com o Supercargo (plano de carga) do navio, sendo elaborado um plano de estivagem ancorado na estabilidade do navio para evitar adernamentos, trim e deflexões.

"O plano de carga é um diagrama do navio onde se assinala, num perfil e em cada convés, a disposição da carga a bordo. A carga é indicada no plano por uma cor para cada porto, de modo que qualquer pessoa possa facilmente localizar que carga deve desembarcar em determinado porto. Além, do porto de destino, usualmente escrevem-se no plano de carga o peso e o nome da mercadoria, e algumas vezes o volume e o número de unidades... O plano de carga é organizado enquanto se processa o carregamento, pois ele deve mostrar a localização real da carga" (FONSECA, 2002).

Ainda, segundo Fonseca (2002), a disposição da carga na embarcação deve obedecer a alguns requisitos, em que primeiro deve-se saber onde se situam as cargas a serem embarcadas, 
o seu peso, volume e o porto de destino. E assim organiza-se a disposição das mercadorias de acordo com o porão e lugar em que deverá ser estivada. Ensina, ainda, o autor a necessidade fundamental de considerar alguns princípios da boa estiva, como:

1. Segurança do navio: tendo basicamente como principais referências os itens estabilidade e distribuição de esforços.

2. Segurança da carga e do pessoal: trata de um bom armazenamento a fim de evitar avarias nas cargas e em caso de cargas perigosas evitar a combustão ou vazamento de gases.

3. Utilização da capacidade total de carga do navio: o plano objetiva utilizar da melhor forma possível toda a capacidade de armazenamento do navio.

4. Distribuição da carga pelos portos de destino: a mercadoria destinada ao primeiro porto da escala precisa necessariamente estar posicionada de forma que seu desembarque seja fácil e assim sucessivamente nos demais portos de destino.

5. Eficiência das operações de carregamento e descarga: operação é tempo e tempo é dinheiro.

Obedecidas essas considerações, o plano de carga é repassado para o Ship planner da Suzano, no qual, após saber qual a sequência dos porões a serem carregados, realiza a identificação e alocação da carga nos porões do navio: dizer qual carga, de qual cliente entrará primeiro no porão do navio. Diante da possibilidade de haver produtos pertencentes a mais de dois clientes em um mesmo porão, a bordo, essas mercadorias são diferenciadas por discretas marcações feitas a pincel colorido ou simplesmente pelo fato da carga ser encapada ou não.

Depois, essa sequência é repassada para o armazém, que, então, realiza o ordenamento dos caminhões para deslocar a carga até a beira do cais. A operação de estivagem pode ser efetuada simultaneamente em dois porões. Assim, é necessário predefinir a sequência exata e em qual porão o caminhão se destinará. Dentro do armazém, garras hidráulicas especializadas no manejo de celulose empilham as cargas nos caminhões, respeitando a sequência e a geometria calculada anteriormente, conquanto, essa carga é deslocada até o berço em que o navio está atracado.

A partir daí, inicia-se a estivagem que é orientada pelo supervisor de bordo, que se baseia na ordem de carregamento anteriormente planejado. Contudo, apesar do planejamento já chegar pronto para o supervisor esse tem autonomia, conhecimento, e rapidez suficiente para perceber alguma anomalia durante a operação, como um adernamento para bombordo ou para boreste. Nesse caso, o supervisor orienta o guindasteiro se a próxima lingada será para o "lado mar" ou "lado terra", entre outras possibilidades.

Toda essa operação é também observada pelos conferentes, os quais são responsáveis por registrar as lingadas de carga durante o carregamento, para fazer a comparação com a lista de carga prevista. Então, é preenchida uma nota de conferência, que é também conhecida por seu nome em inglês: tallyo, documento esse que contém informações como as interrupções, o tempo e o motivo que as causaram. Esses documentos serviram para a análise a seguir. 


\section{Resultados e discussões}

Este item apresenta a análise dos dados de campo da pesquisa, embasada no que Fonseca (2002) orienta:

Ao mesmo tempo em que se assegura a melhor disposição de peso e volume de carga pelo navio, é preciso considerar a eficiência e rapidez das operações de carregamento e descarga. A disposição da carga destinada a um mesmo porto deve ser feita equitativamente por todos os porões. Assim, se poderá operar em todas as escotilhas durante a descarga; deve-se levar em conta que a estadia de um navio no porto será tão prolongada quanto o for o trabalho na escotilha que tiver maior quantidade de carga. Muitas vezes é preferível recorrer ao pagamento extraordinário de um terno de estiva para terminar o serviço numa escotilha, evitando demora muito maior do navio por perda de maré favorável, ou por ser depois de um dia feriado, por exemplo (FONSECA, 2002, p. 703).

A partir de então, questiona-se: As estratégias empregadas na estivagem de celulose no Porto do Itaqui vêm diminuindo o tempo de operação? Para observar a operação de estivagem, foi realizado um acompanhamento com o supervisor de Bordo e com os estivadores do OGMO.

O cálculo das paralisações durante a operação baseia-se em informações contidas nos tallyos de três navios, cujos motivos dessas paralisações são descritos e apresentados nas imagens gráficas a seguir:
A) Defeito nos spreaders
B) Alinhamento de carga
C) DDS
D) Preparativos
E) Avaria na carga
F) Manutenção no guindaste
G) Abertura / Troca de porão
H) Apeação
I. Posicionamento da plataforma
J) Falta de carga
K) Ameaça de chuva
L) Outros

\subsection{Análise Gráfica das Paradas Operacionais}

Com base nas informações do Centro de Controle de Operações, calcularam-se os minutos de cada interrupção durante a operação, depois esses valores foram convertidos em gráfico de Paretos, a fim de facilitar a visualização e identificação dos problemas, possibilitando a elaboração de um sistema de priorização das causas para depois partir para identificação das causas. 


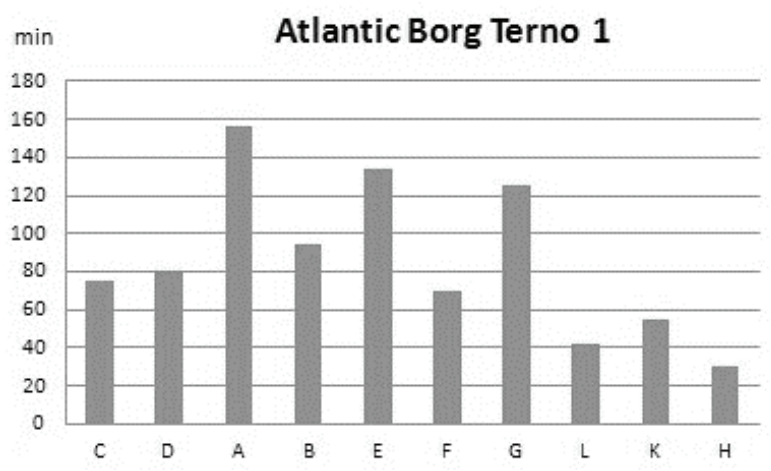

Gráfico 1 - Tempo das Paralisações Operacionais

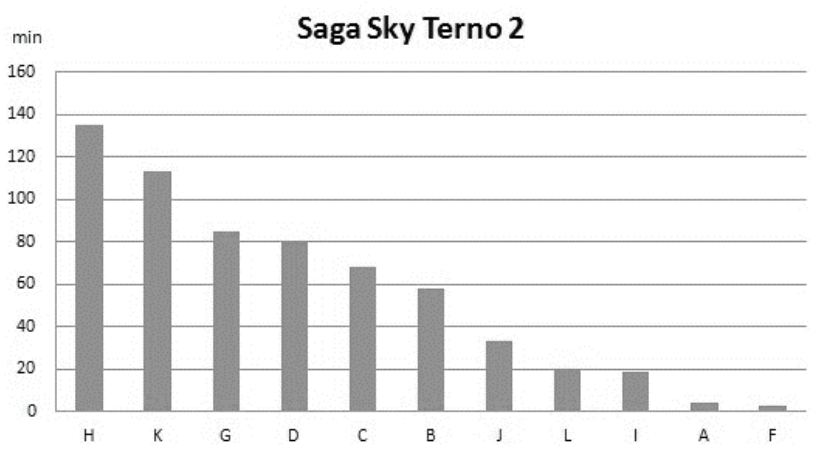

Gráfico 3 - Tempo das Paralisações Operacionais

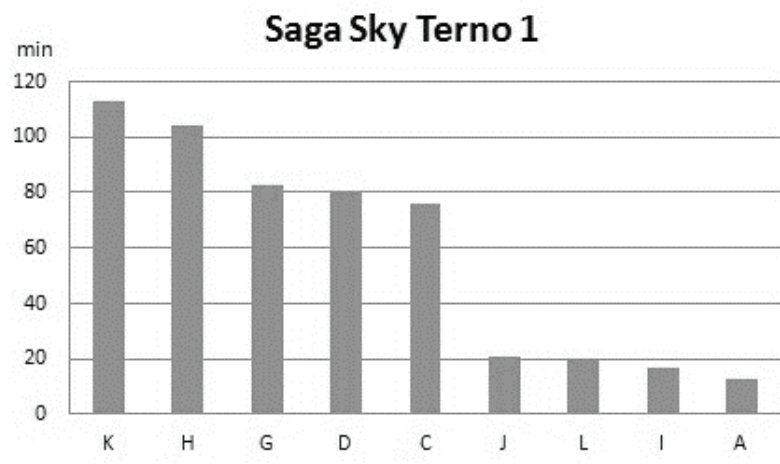

Gráfico 2 - Tempo das Paralisações Operacionais

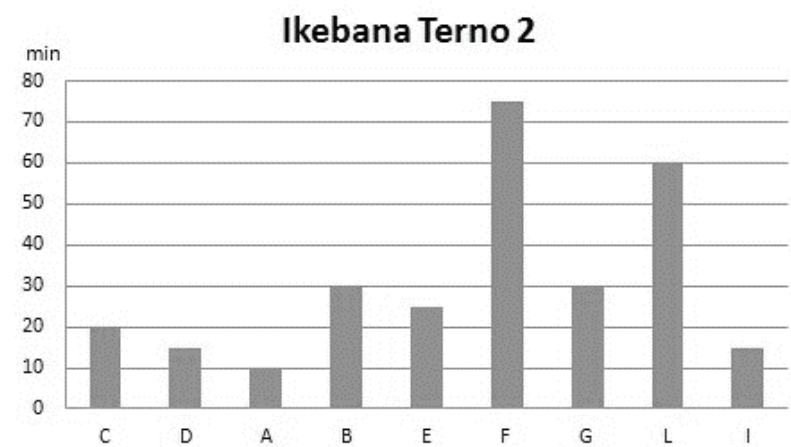

Gráfico 4 - Tempo das Paralisações Operacionais

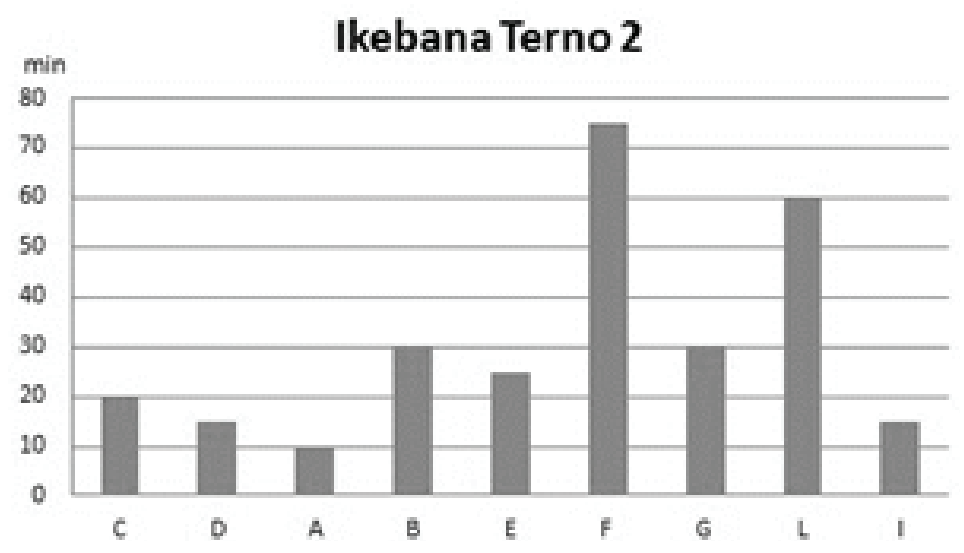

\subsection{Análise das Paradas Operacionals}

Silva (2012) esclarece a situação observada em campo, no qual discorre a respeito das paralisações ocorridas durante as operações: 
Uma significativa parte do tempo em que o equipamento deveria estar a funcionar, efetivamente está parado ou a funcionar em condições que não permitem produzir à cadência ideal. O impacto negativo na produtividade e nos custos é enorme e, frequentemente, é esta situação que está na origem da falta de cumprimento dos prazos de entrega ao cliente ou nas rupturas de stock nos armazéns. Infelizmente, os clássicos mecanismos contabilisticos de controle de custos não refletem a "realidade" das fábricas. Se o fizessem, certamente a vida dos responsáveis das operações seria muito mais complicada, pois mostraria a "Fábrica Escondida" que existe em todas as unidades fabris, chamando-lhes a atenção para o "Verdadeiro Custo das Paragens" e das perdas em geral (SILVA, 2012, p. 2).

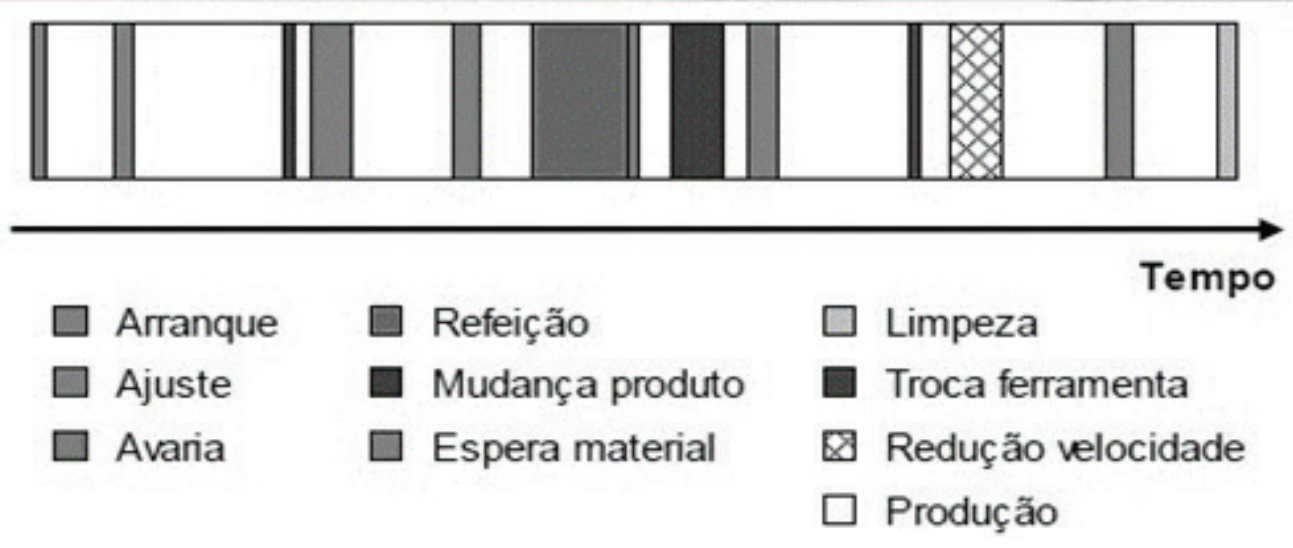

Figura 6 - Período de funcionamento dos equipamentos.

Fonte: SILVA, 2010.

A Figura 6 apresenta como operam a maioria das máquinas, e, em uma unidade de estivagem de celulose não é diferente, com base nas pesquisas de campo foi possível dar o terceiro passo para a mitigação dos problemas segundo a metodologia da estratégia gerencial Seis Sigma, em que se observam e se analisam os fatores que colaboram para essas paradas operacionais sendo estes:

Defeito no Spreader - Observamos que a operação sofre várias pequenas interrupções para a efetuar a manutenção corretiva na mangueira a ar comprimido que tem a função de abrir o gancho pneumático, tal situação acontece devido a uma presilha não estar bem fixada, como mostra a Figura 6, bem como, a mangueira poder estar desgastada devido ao tempo de uso ou até mesmo por uma falta de habilidade, ou entrosamento do guindasteiro com o equipamento, ocasionando um mau uso. 


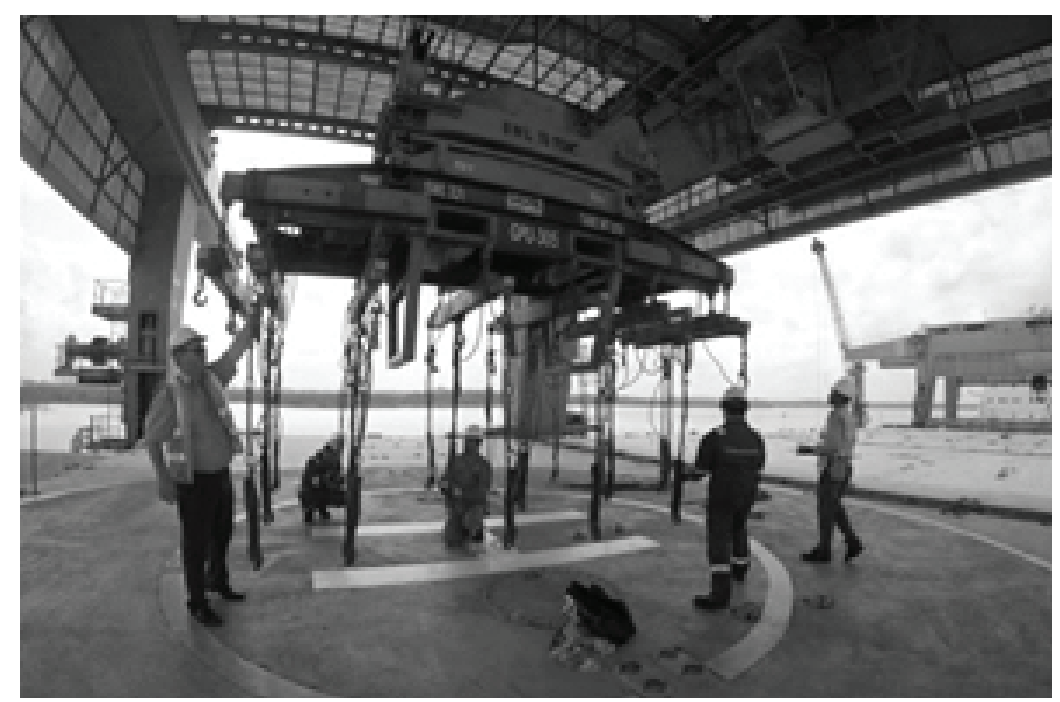

Figura 7 - Manutenção no Spreader.

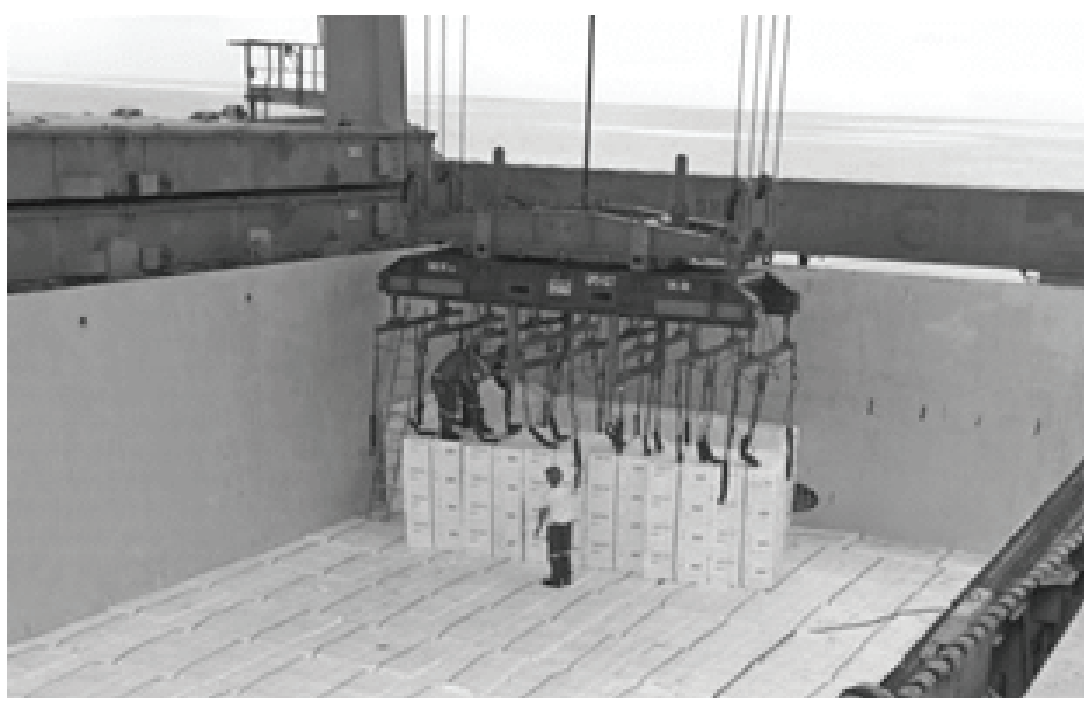

Figura 8 - Colaborador reencaixando o gancho na carga.

Alinhamento de carga - Identificamos alguns fatores que contribuem para esse fator, por exemplo, o fato de um mau uso do engate do gancho na carga, propiciando que ela seja içada de forma desuniforme, e assim dificultando o trabalho do guindasteiro ao ter que posicionar a mercadoria no porão, sendo que, às vezes, é necessário ter que abaixar a carga no porão para que sejam recolocados os ganchos, gerando um retrabalho e, por conseguinte, um atraso na operação. Mas esse mau uso do engate do gancho na carga também pode estar relacionado à geometria do gancho.

Nesse aspecto, a falta de habilidade do guindasteiro e o entrosamento com a máquina também colaboram, pois o campo de visão que esse profissional tem de cima do guindaste é 
um tanto quanto limitado em relação à perspectiva de profundidade, que é algo que o profissional adquire com o tempo de trabalho.

D.D.S - Apesar do diálogo de segurança estar presente na maioria dos tallyos, porém, este não deve ser considerado como uma paralisação na operação pois ele objetiva justamente o contrário a fim de evitar acidentes além de que são passados alguns pontos sobre a operação.

Preparativos - Engloba exatamente o momento de posicionar a ponte rolante, de conectar os spreaders, muitas das vezes a manutenção é feita só nesse momento em que o navio já atracou estando apto a operar e não antes de sua atracação a fim de evitar perda de tempo.

Avaria na carga - Essas paralisações geralmente são causadas quando pinga óleo proveniente do guindaste na carga, quando há um rompimento dos arames que unitizam a celulose ou quando se observa que foi embarcada uma carga muito avariada devido ao manuseio dela pelas empilhadeiras.

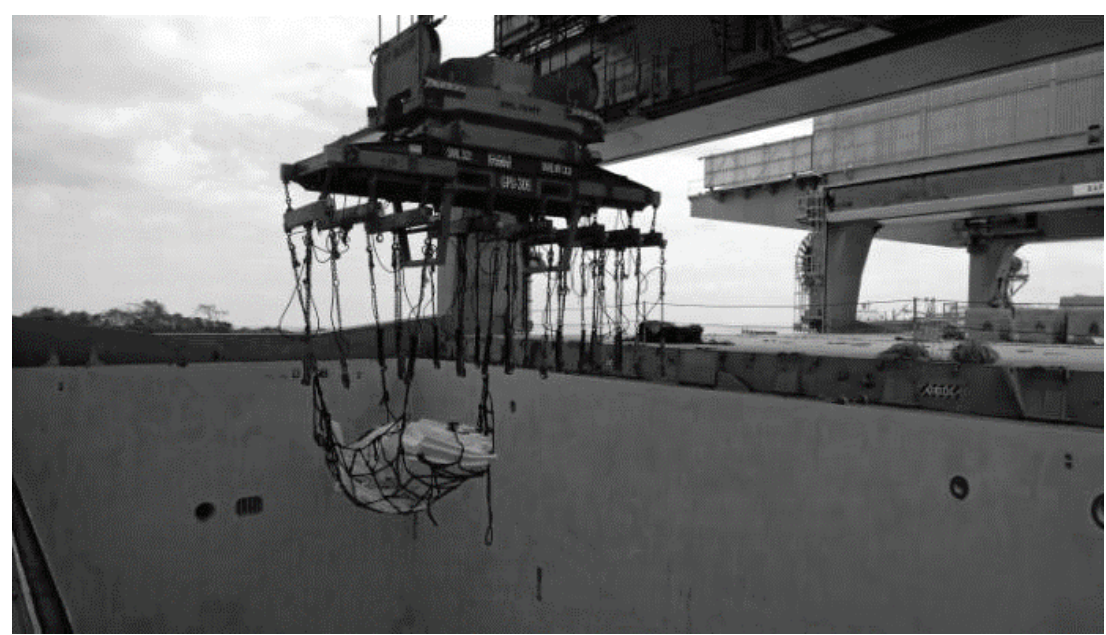

Figura 9 - Retirando carga avariada.

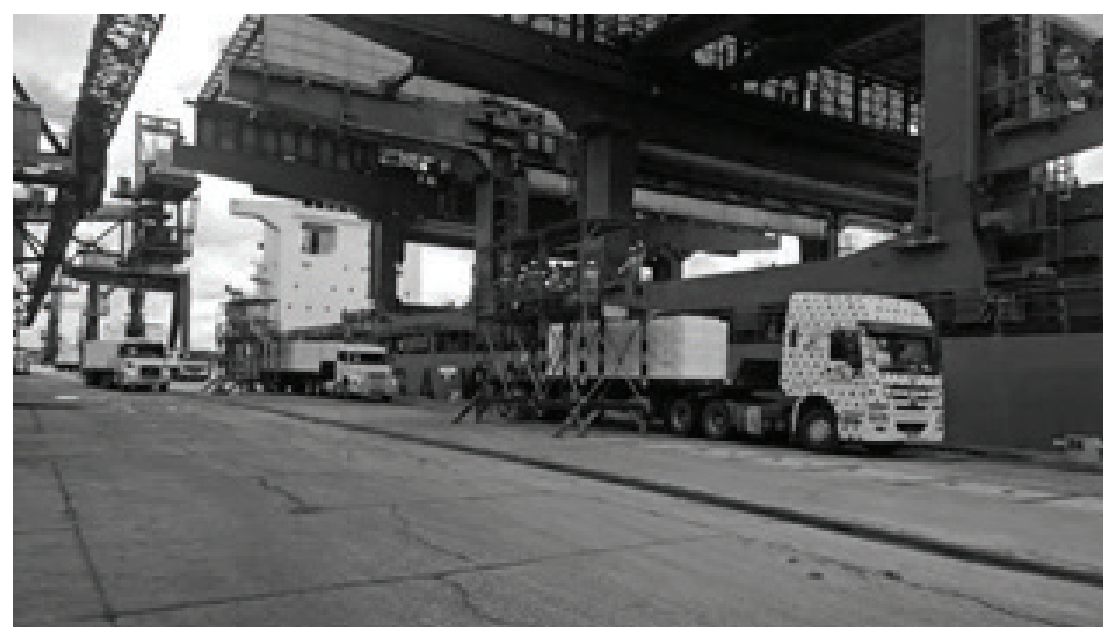

Figura 10 - Operação em andamento. 
Manutenção no guindaste - Essa paralisação é constante e na maioria das vezes ocorre devido ao tempo de uso dos equipamentos.

Abertura e troca de porão - Em entrevista com funcionários da G5 Logística, foi constatada a observação de que ultimamente os navios vêm reduzindo a sua tripulação e essa redução impacta diretamente na mudança de porão, pois a atividade que antes era desempenhada por vários colaboradores agora é executada por muito menos funcionários.

Apeação - Esse é o momento em que é feita uma amarração entre os fardos da última camada estivada no porão a fim de impedir que estes se desloquem dentro do porão e assim evitem também que os fardos das outras camadas se movimentem também. Às vezes, são feitas duas apeações em um mesmo porão. Isto ocorre quando há camadas destinadas a portos diferentes.

Posicionamento da plataforma - A plataforma é uma estrutura metálica que abriga os arrumadores e que tem a função de conectar o gancho do spreader nos fardos, conforme a Figura 10. Essa paralisação poderia ser evitada caso o posicionamento da plataforma fosse feito no mesmo período da troca de porão.

Falta de carga - Ocorre muitas vezes pelo fato da produção não acompanhar a demanda ou por um problema durante o transporte de Imperatriz até São Luís.

Ameaça de chuva - É uma causa natural que impacta muito a operação e que não pode ser controlada, agrava-se ainda também, pois em São Luís há um período chuvoso contínuo em torno de cinco meses. Porém, no momento em que está chovendo todas as operações são paralisadas e também não há cobrança pelo aluguel do berço atracado.

Outros - Neste quesito estão as paralisações que não ocorrem com frequência, mas estavam presentes nos tallyos e também afetam de alguma forma a produtividade. Podemos citar como intervenções da EMAP para inspeção de segurança ou meio ambiente, a falta de caminhões na beira do cais, a espera pelos armadores, parada solicitada pelo navio, remover e encher bag, movimentação de shiploader, caminhão obstruindo a passagem, manifestação, troca de turno e troca de guindaste etc.

\subsection{Análise do Desempenho Operacional segundo o OEE}

O Overhaul Equipment Effectiveness (Eficácia Global do Equipamento) OEE é um indicador utilizado para medir o desempenho de uma máquina em uma operação fundamentado no tempo útil que o equipamento tem para funcionar, baseia-se na eficiência demonstrada durante o funcionamento e a qualidade do produto obtido durante o processo.

O OEE teve origem no TPM - Total Productive Maintenance, parte integrante do TPS - Toyota Production System e o seu criador, Seiichi Nakajima, desenvolveu o como meio de quantificar não apenas o desempenho dos equipamentos, mas também como métrica da melhoria contínua dos equipamentos e processos produtivos. Com a adoção dos conceitos do TPS por inúmeras empresas japonesas e com o desenvolvimento do Lean Manufacturing no ocidente, o OEE tornou-se o referencial mundial para medição do desempenho dos equipamentos das empresas industriais (SILVA, 2012, p. 4). 
Ainda com base no texto de Cutrim (2015 apud HUTCHINS, 2008) "O OEE exprime a eficiência da máquina ou da operação e é calculado pelas relações entre a produção real e a padrão ou entre o tempo padrão da operação e o real de execução".

Moellmann et al. (2006) indicam que quanto mais próximo de 1 (100\%) for o índice OEE, tanto mais produtiva será a linha de produção. Santos e Santos (2007) acrescentam que esse índice, ao medir o desempenho de equipamentos e máquinas ou o seu conjunto, identifica os de menor índice de eficiência e, também, de perdas.

Hutchins (2008) aponta que na implantação da ferramenta OEE o controle separado de indicadores de disponibilidade de equipamentos, do seu desempenho operacional e da qualidade da operação com agregação posterior para gerenciamento e controle. pode levar a ganhos expressivos de desempenho, produtividade e à redução de custos.

Segundo Silva (2012), há de se lembrar que esse indicador não é a solução dos problemas na linha de produção, ele é para identificar e quantificar os problemas detectados, anuncia o quão eficaz está o equipamento e por meio de comparação de dados permite avaliar o efeito das ações tomadas no intuito de tornar o equipamento mais eficaz.

Silva (2012) também afirma que as empresas que adotam a medição e aplicam as devidas mudanças operacionais alcançam um rápido aumento do OEE entre 5 e 20 pontos percentuais, sendo que este pode duplicar no período de um ano, dependendo da sua nota de partida. Afirma também que quanto maior o OEE tanto mais difícil é melhorá-lo. Como referência de classe mundial baseia-se na casa dos $85 \%$, no entanto assevera que empresas que adotaram o Lean em sua gestão são capazes de alcançar valores superiores a 90\% de OEE.

Tabela 1 - Terno 1 do navio Saga Sky.

\begin{tabular}{|l|c|l|}
\hline \multicolumn{3}{|c|}{ Saga Sky Terno 1 } \\
\hline Fator Disponibilidade & 91,92 & $\%$ \\
\hline Fator Eficiência & 98,63 & $\%$ \\
\hline Fator Qualidade & 100 & $\%$ \\
\hline Eficácia Global do Equipamento & 90,66 & $\%$ \\
\hline
\end{tabular}

Tabela 3 - Terno 1 do navio Ikebana.

\begin{tabular}{|l|c|l|}
\hline \multicolumn{3}{|c|}{ Ikebana Terno 1 } \\
\hline Fator Disponibilidade & 76,88 & $\%$ \\
\hline Fator Eficiência & 97,90 & $\%$ \\
\hline Fator Qualidade & 99,84 & $\%$ \\
\hline Eficácia Global do Equipamento & 75,15 & $\%$ \\
\hline
\end{tabular}

Tabela 2 - Terno 2 do navio Saga Sky.

\begin{tabular}{|l|r|r|}
\hline \multicolumn{3}{|c|}{ Saga Sky Terno 2} \\
\hline Fator Disponibilidade & 89,83 & $\%$ \\
\hline Fator Eficiência & 99,95 & $\%$ \\
\hline Fator Qualidade & 100 & $\%$ \\
\hline Eficácia Global do Equipamento & 89,79 & $\%$ \\
\hline
\end{tabular}

Tabela 4 - Terno 2 do navio Ikebana.

\begin{tabular}{|l|r|l|}
\hline \multicolumn{3}{|c|}{ Ikebana Terno 2} \\
\hline Fator Disponibilidade & 80,2778 & $\%$ \\
\hline Fator Eficiência & 99,4879 & $\%$ \\
\hline Fator Qualidade & 100 & $\%$ \\
\hline Eficácia Global do Equipamento & 79,8667 & $\%$ \\
\hline
\end{tabular}


Tabela 5 - OEE Atlantic Borg.

\begin{tabular}{|l|r|l|}
\hline \multicolumn{3}{|c|}{ Atlantic Borg Terno 1 } \\
\hline Fator Disponibilidade & 77,05 & $\%$ \\
\hline Fator Eficiência & 99,84 & $\%$ \\
\hline Fator Qualidade & 98,4 & $\%$ \\
\hline Eficácia Global do Equipamento & 75,71 & $\%$ \\
\hline
\end{tabular}

Como já foi exposto, quanto mais próximo de 100\% tanto mais produtiva é a linha de produção e que a nível mundial as empresas buscam operar dentro dos 85\%. Então, a partir dos dados mencionados, é possível perceber que somente as linhas de estivagem do Saga Sky bateram essa meta, porém os outros dois ficaram muito afastados desse índice. Observa-se também que os navios apresentam características semelhantes no fator eficiência e no fator qualidade, isso se dá porque o fator eficiência mede a quantidade de produtos finalizados e no caso do navio ele tem que transportar a quantidade exata exigida pelo comprador. O mesmo se aplica para o fator qualidade onde se exige também que sejam embarcados somente fardos que não estejam avariados, por isso esse ponto costuma atingir o padrão máximo, isso não quer dizer que não houve cargas avariadas durante a operação, mas sim que todas foram substituídas.

\section{CONSIDERAÇÕES FINAIS}

Observou-se que, embora a empresa possua um alto grau de organização e produção, comprovado pelo indicador de eficiência global do equipamento, foram notadas falhas isoladas que podem resultar em perdas a serem mitigadas.

Dessa forma, a intenção é dar continuidade às pesquisas, conquanto, como próximo passo, pretende-se fazer uma avaliação de eficiência baseada em dados anuais, com a finalidade de adaptar melhor o cálculo de fator de eficiência à realidade da operação de estivagem de celulose, levando-se em consideração que apenas a análise de três embarcações não se mostra suficiente para determinar o OEE de uma empresa. Entende-se, por fim que, em razão deste estudo, nos será permitido analisar os entraves e, por conseguinte, propor as devidas soluções para amenizar essas intervenções durante a operação.

\section{ReFERÊNCIAS}

COUTO, H. F. Benefício da Unitização de Cargas na Cadeia Logística. Rio de Janeiro, 2007.

CUTRIM, S. S.; ROBLES, L. T.; ROMA NETO, P.; CUTRIM, S. J. Gestão de falhas na descarga de minérios no terminal marítimo de Ponta da Madeira. Revista de Ciência \& Tecnologia, v. 17, p. 27-50, 2014b.

44 Revista de Ciência \& Tecnologia • v. 21, n. 41, p. 31-45 • 2017 • ISSN Impresso: 0103-8575•ISSN Eletrônico: ISSN: 2238-1252 
FONSECA, M. M. Arte Naval Volume I, 6. ed. Rio de Janeiro: Serviço de Documentação da Marinha, 2002.

ROJAS, P. Introdução à logística portuária e noções de comercio exterior. Porto Alegre: Bookman, 2014.

SILVA, J. P. OEE - A Forma de Medir a Eficácia dos Equipamentos. Portugal, 2012.

Submetido em: 5-9-2018

Aceito em: 7-11-2018 